\title{
ANÁLISE DE MODELOS TROPOSFÉRICOS NO POSICIONAMENTO BASEADO EM REDES USANDO O CONCEITO DE VRS
}

Analysis of tropospheric models for network based positioning using the concept of VRS

ADELITON DA FONSECA DE OLIVEIRA ${ }^{1}$
DANIELE BARROCA MARRA ALVES
LUIZ DANILO DAMASCENO FERREIRA $^{3}$

${ }^{1}$ Instituto Federal Baiano - IF Baiano - Campus Uruçuca

R. Dr. João Firmino Nascimento S/N - CEP: 45680-000 - Uruçuca - BA

${ }^{2}$ Universidade Estadual Paulista - UNESP - FCT

R. Roberto Simonsen 305, CEP: 19060-900 - Presidente Prudente - São Paulo

${ }^{3}$ Universidade Federal do Paraná - UFPR

Caixa Postal 19001 - CEP: 81531-980 - Curitiba - PR

adelitonoliveira@yahoo.com.br; danibarroca@fct.unesp.br; luizdanilo@ufpr.br

\section{RESUMO}

Nos últimos anos, várias técnicas de posicionamento GPS (Global Positioning System) vêm sendo desenvolvidas e/ou aprimoradas com interesse de alcançar alta acurácia e produtividade em tempo real. O conceito de redes de estações de referência além de possibilitar aos usuários das comunidades civis e científicas qualidade e confiabilidade no posicionamento, permite estudos sobre a modelagem da refração troposférica na região da rede. Além disso, dentre as formas de transmissão das correções geradas pela rede ao usuário, destaca-se o conceito de VRS (Virtual Reference Station). Neste método, os dados de uma estação virtual são gerados nas proximidades do usuário, permitindo realizar posicionamento relativo em linhas de base curta com receptor de simples frequência. Neste artigo é descrita a metodologia para geração de dados da VRS com diferentes modelos troposféricos. Foram realizados testes comparativos nas quatro estações do ano com os modelos troposféricos de PNT/INPE (Previsão Numérica de Tempo/Instituto Nacional de Pesquisas Espaciais) e Hopfield. Na análise de qualidade dos dados da VRS, o 
método PPP (Posicionamento por Ponto Preciso) proporcionou resultados satisfatórios. Foram observadas melhorias entre os modelos de PNT/INPE e Hopfield de $9,75 \%$ e $24,2 \%$ em média para dias secos e úmidos, respectivamente.

Palavras-chave: VRS; RTK em Rede; Modelos Troposféricos.

\section{ABSTRACT}

In the past few years several GPS (Global Position System) positioning techniques have been develope and/or improved with the goal of obtaining high accuracy and productivity in real time. The reference station network concept besides to enabling quality and reliability in positioning for scientific and civil GPS community, allows studies concerning tropospheric refraction modeling in the network region. Moreover, among the network corrections transmission methods available to users, there is the VRS (Virtual Reference Station) concept. In this method, the data of a virtual station are generated near the rover receiver (user). This provides a short baseline and the user has the possibility of using a single frequency receiver to accomplish the relative positioning. In this paper, the methodology applied to generate VRS data, using different tropospheric models is described. Thus, comparative tests were conducted in the four seasons with the NWP/INPE (Numerical Weather Prediction/National Institute for Space Research) and Hopfield tropospheric models. In order to analyse the VRS data quality, it was used the Precise Point Positioning (PPP) method, where satisfactory results were found. Mean differences between PNT/INPE and Hopfield models of $9.75 \%$ and $24.2 \%$ for the hydrostatic and wet days, respectively were obtained.

Keywords: VRS; Network RTK; Tropospheric Models.

\section{INTRODUÇÃO}

Atualmente, existe um conjunto de sistemas de posicionamento global operando ou em fase de desenvolvimento/modernização, dentre os primeiros sistemas destacam-se o norte americano GPS (Global Positioning System), seguido do GLONASS (Global Orbiting Navigation Satellite System). Em relação aos sistemas em desenvolvimento, cita-se, o Galileo, e o sistema Beidou/Compass (SEEBER, 2003; LEICK, 2004; MONICO, 2008).

Esses sistemas em conjunto, além dos sistemas regionais SBAS (Satellite Based Augmentation System) compõem a tecnologia GNSS (Global Navigation Satellite System) (MONICO, 2008).

Os receptores GNSS podem coletar dados para a realização de posicionamento em tempo real com acuracidade a nível centimétrico (DAI et al., 2003). Uma possibilidade é o uso do método denominado RTK (Real Time Kinematic), onde são empregados dois receptores, um deles denominado estação base, fica posicionado em um ponto de coordenadas conhecidas, enquanto outro receptor, denominado móvel (usuário ou rover), realiza o posicionamento dos pontos de interesse. No entanto, devido à influência dos erros dependentes da distância (ionosfera, 
troposfera e órbita dos satélites), o RTK fica limitado apenas para aplicações em linhas de base curta (menores que $20 \mathrm{~km}$, dependendo das condições ionosféricas), devido ao fato dos efeitos atmosféricos serem proporcionais ao comprimento da linha de base, degradando a posição do receptor móvel (KRUGER, 1996; PRADO e KRUEGER, 2003; RAMOS, 2007; ALVES, 2008; MONICO, 2008). A fim de superar esse problema, surgiu o posicionamento RTK em rede. O uso de dados das redes GNSS permite a modelagem dos erros atmosféricos (ionosfera e troposfera) que atuam no posicionamento, evitando a degradação da posição do receptor móvel. Dessa forma, a área de atuação do usuário aumenta significativamente.

Neste artigo, é descrito e investigado a aplicação de diferentes modelos troposféricos no posicionamento em Redes, empregando o conceito de estação virtual, considerando períodos críticos (seco e úmido) ao longo das quatro estações do ano, onde foram empregados dados da rede GNSS/SP. É importante destacar que os experimentos deste artigo foram realizados no modo pós-processado, simulando uma aplicação em tempo real. Além disso, os dados gerados para as estações virtuais foram avaliados com o método de posicionamento por ponto. Os modelos troposféricos utilizados foram os de PNT do CPTEC/INPE e o modelo empírico de Hopfield. Aspectos teóricos, resultados e análises seguem nas próximas seções.

\section{POSICIONAMENTO BASEADO EM REDE}

O emprego dos dados de múltiplas estações de referência é uma realidade em muitos países, como na Alemanha, devido à busca de informações espaciais e posicionamento acurado em tempo real. No posicionamento RTK em rede, existe a possibilidade de ampliar a distância entre as estações da rede e a posição do receptor móvel, além de proporcionar alta acurácia, disponibilidade e confiabilidade no posicionamento e na navegação (ALVES, AHN e LACHAPELLE, 2003; ALVES, 2008).

A arquitetura de uma rede RTK compreende um conjunto de estações de referência GNSS, um ou mais sistemas de comunicação (rádio, internet e etc.) para coleta e envio de correções ao usuário e um centro de controle para gerenciamento dos dados (AFONSO, 2006). Para a aplicação deste conceito, é necessário estabelecer comunicação entre as estações que compõe a rede e o usuário. De acordo com RAMOS (2007) o enlace (link) de dados entre a estação de referência e a móvel irá depender do volume de dados a ser transmitido, do número de satélites rastreados, tipo e formato dos dados, requisitos de integridade e confiabilidade, condições de operação e comprimento da linha de base.

Um fator importante que deve ser levado em consideração é quanto ao método de transmissão de correções ao usuário. Dentre eles, destacam-se o FKP/ACP (Flächenkorrekturparameter/Area Correction Parameters) (EULER et al., 2001; SEEBER, 2003 e SOARES, 2005), MAC (Master-Auxiliary Concept) (EULER et al., 2001), RTX (Real-Time Extended) (CHEN et al., 2011 e LEANDRO et al., 2011) e a VRS (Virtual Reference Station) (LANDAU et al., 2002; SEJAS 
et al., 2003, ALVES, 2008; ALVES e MONICO, 2011). Dentre os métodos de transmissão de correções, o conceito de VRS é abordado neste artigo.

\section{VRS}

No conceito de VRS, dados virtuais para uma estação de referência são gerados próximo ao receptor do usuário, ou seja, distâncias inferiores a $20 \mathrm{~km}$, dependendo das condições ionosféricas por exemplo. Ao invés de enviar correções da rede diretamente ao usuário, observações são geradas para uma posição próxima do mesmo (VOLATH et al., 2000; LACHAPELLE e ALVES, 2002).

No método de VRS, o usuário recebe as correções da rede na forma de uma estação que não existe fisicamente. Para aplicar o conceito de VRS na prática, dados GPS da rede de referência são enviados continuamente via rede de comunicação para o centro de controle. O computador central, munido de softwares específicos utiliza os dados coletados para modelar as principais fontes de erros sistemáticos que degradam a acurácia do posicionamento. Assim, correções são geradas na forma de um arquivo RINEX (pós-processamento) com observações de fase e código e enviadas para o usuário em qualquer posição da rede (ZHANG e ROBERTS, 2003; HOFMANNWELLENHOF, LICHTENEGGER e WASLE, 2008). Dessa forma, o usuário pode realizar posicionamento relativo empregando a VRS como uma estação de referência nas suas proximidades.

Já no posicionamento em tempo real, a posição aproximada do usuário é enviada ao computador central na mensagem padrão NMEA (National Marine Electronics Association) via comunicação bidirecional (Figura 01). Essa comunicação é realizada via internet ou utilizando telefones móveis via GSM (Global System for Mobile Communications). O centro de controle recebe as coordenadas da posição e responde enviando dados da VRS no formato RTCM, simulando uma estação de referência fictícia (LANDAU et al., 2002; VOLLATH et al., 2000).

Figura 01 - Conceito de Estações de Referência Virtual.

Fonte: Adaptado de Landau et al. (2002).

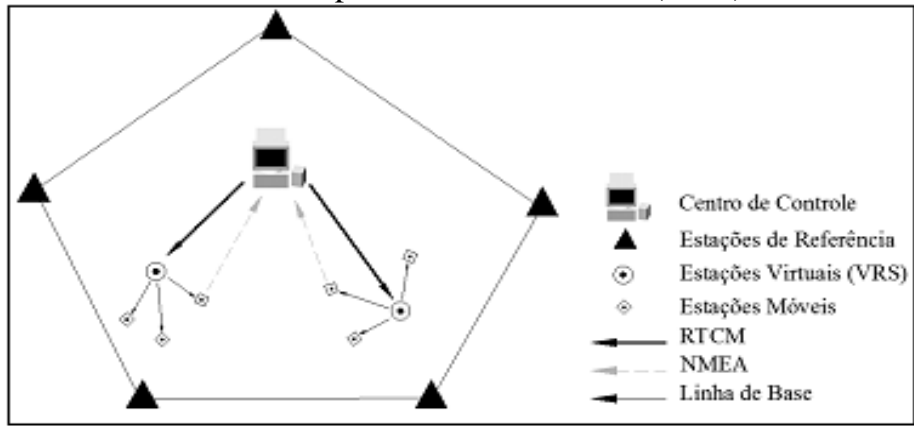

Bol. Ciênc. Geod., sec. Artigos, Curitiba, v. 20, nº 1, p. 39-53, jan-mar, 2014. 


\section{MODELOS TROPOSFÉRICOS}

No sistema GNSS existe uma série de efeitos e erros que atuam sobre o posicionamento degradando a acurácia dos resultados. Dentre eles, a troposfera é considerada a segunda maior fonte dos erros que atuam em sinais de radiofrequência da banda L (L1 e L2), sinais com os quais o GPS opera (SEEBER, 2003). Sapucci (2001) explica que o atraso troposférico é causado pela variação do índice de refração dos gases que compõe a troposfera. Devido a essa variação, a trajetória do sinal sofre uma leve curvatura quando comparada à sua trajetória geométrica entre um satélite e o usuário em terra. Logo, conclui-se que o índice de refração provoca mudanças na direção e velocidade dos sinais eletromagnéticos propagados.

Os dois modelos para troposfera empregados nessa pesquisa são: o modelo empírico de Hopfield e a modelagem dinâmica com o uso dos modelos de PNT do CPTEC/INPE (Centro de Previsão de Tempo e Estudos Climáticos). Sapucci et al (2003) esclarece que o princípio de funcionamento da modelagem dinâmica é bastante simples: conhecendo as leis de evolução do estado da atmosfera, pode-se calcular o seu estado futuro no instante $t$, desde que seja conhecido com precisão seu estado inicial no instante $t_{0}$.

Na modelagem dinâmica baseada em modelos de PNT, o atraso zenital total ZTD (Zenithal Tropospheric Delay) é dado em função da soma das componentes úmida ZWD (Zenithal Wet Delay) com efeito da quantidade de vapor d'água na atmosfera e hidrostática ZHD (Zenithal Hydrostatic Delay) pela influência de demais gases incluindo o vapor d'água.

Assim, tem-se que o atraso zenital é dado pela seguinte equação (SPILKER et al.,1996):

$$
Z_{T D}=Z_{H D}+Z_{W D}=10^{-6} \int_{h_{0}}^{\infty} k_{1} R_{h} \rho d h+10^{-6} \int_{h_{0}}^{\infty}\left(k_{2}^{\prime} \frac{e}{T} Z_{w}^{-1}+k_{3} \frac{e}{T^{2}} Z_{w}^{-1}\right) d h
$$

Onde:

$Z_{T D}$ é o atraso zenital total;

$Z_{H D}$ é o atraso zenital na componente hidrostática;

$Z_{W D}$ é o atraso zenital na componente úmida;

$R_{h}$ é a constante específica para os gases hidrostáticos $\left(R_{h}=287,0538\right.$ $\left.J \mathrm{~kg}^{-1} \mathrm{~K}^{-1}\right)$

$\rho$ é a densidade do ar;

$k_{1}, k_{2}^{\prime}$ e $k_{3}$ são constantes da refratividade atmosférica $\left(k_{1}=77,60 \mathrm{KhPa}^{-1}\right.$,

$k_{2}^{\prime}=22,10 \mathrm{KhPa}^{-1}$ e $k_{3}=373900 \mathrm{~K}^{2} h \mathrm{~Pa}^{-1}$ );

$Z_{w}^{-1}$ é o inverso da constante de compressibilidade do vapor d'água.

O CPTEC disponibilizou a versão inicial da modelagem dinâmica em meados de 2004. Nesse modelo, os valores das componentes ZWD e ZHD eram dispostos em uma malha de 500 por $500 \mathrm{~km}$ para a América Latina, onde cada elemento da malha possuía um arquivo com os dados cuja resolução era de $100 \mathrm{~km}$ na horizontal (denominado de GLB $100 \mathrm{~km}$ ) e 18 níveis na vertical, com 66 horas de predição. Posteriormente, no ano de 2008 a versão inicial sofreu atualizações na modelagem 
de PNT, e a resolução horizontal passou a ser de $20 \mathrm{~km}$ (denominado eta $20 \mathrm{~km}$ ) com 19 níveis verticais e 72 horas de predição do atraso zenital (SAPUCCI et al., 2008).

No ano de 2012, o CPTEC disponibilizou a última versão denominado eta $15 \mathrm{~km}$ (grade de $15 \times 15 \mathrm{~km}$ ), com previsão de até sete dias dos dados meteorológicos, com saídas do modelo a cada três horas, ou seja, oito previsões por dia. No entanto, essa versão ainda encontra-se em fase de testes e consolidação. Por isso, neste artigo, não foi adotado o eta $15 \mathrm{~km}$ na geração dos dados da VRS.

Alves et al (2009) apresentou resultados iniciais da comparação entre Hopfield e PNT/INPE. Mas, naquele momento o produto disponível pelo CPTEC/INPE possuía uma resolução horizontal de $100 \mathrm{~km}$. Nesse artigo é empregado um produto de maior qualidade, o eta $20 \mathrm{~km}$, cuja resolução horizontal é de $20 \mathrm{~km}$. Além disso, é realizada uma análise mais rigorosa, considerando as 4 estações do ano, além de levar em consideração os dias mais úmidos e secos.

\section{5. ÁREA DE ESTUDOS}

A região de estudos desta pesquisa é composta por seis estações que pertencem à rede GNSS do estado de São Paulo (Figura 02). Esta rede é constituída em sua totalidade por 15 estações de monitoramento contínuo com receptores de dupla frequência (L1 e L2), sendo que a maior parte das estações estão homologadas pelo IBGE.

Figura 02 - Estações da rede GNSS/SP e sua localização no estado de São Paulo.

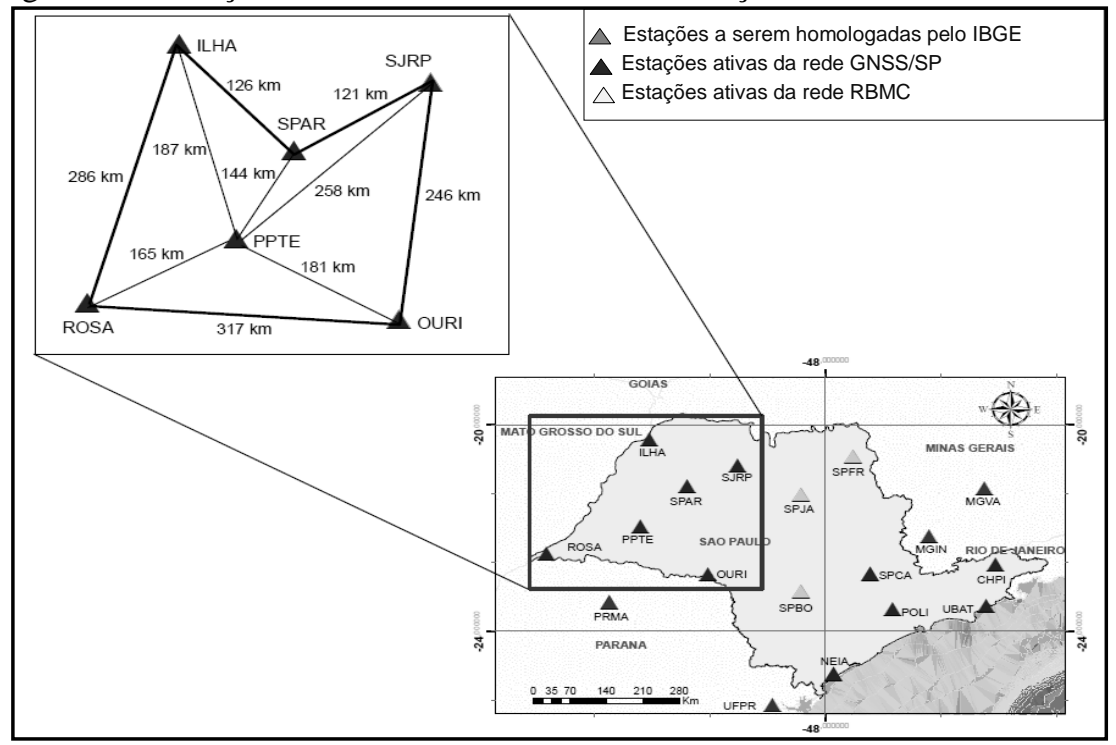

Bol. Ciênc. Geod., sec. Artigos, Curitiba, v. 20, nº 1, p. 39-53, jan-mar, 2014. 
A geometria e densidade das estações que compõem a rede permite a realização de estudos atmosféricos na região, bem como o posicionamento baseado em redes, dentre outras aplicações.

\section{METODOLOGIA}

Nessa pesquisa se empregou uma metodologia diferenciada desenvolvida por Alves (2008), que consiste em gerar dados de VRS empregando correções atmosféricas (modelagem troposférica e ionosférica) e sem solucionar as ambiguidades da rede.

Um software científico desenvolvido em ambiente $\mathrm{C}++$, denominado VRS UNESP, capaz de gerenciar dados da rede de estações de referência e gerar dados de VRS no modo pós-processado utilizando modelos atmosféricos foi utilizado para geração dos dados das VRSs nesse artigo.

Os dados RINEX (Receiver Independent Exchange Format) das estações de referência de ILHA (Ilha Solteira), ROSA (Rosana), OURI (Ourinhos), SJRP (São José do Rio Preto), SPAR (Araçatuba) e PPTE (Presidente Prudente) foram obtidos através do banco de dados do IBGE, em dias críticos (úmidos e secos) para as quatro estações do ano. A escolha desses dias críticos foi realizada através de dados gerados de uma série temporal de valores de ZTD compreendendo o período de um ano, conforme a Figura 03. Para tanto, foram empregados dados do software científico GIPSY-OASIS II (GOA II) para estimativa do atraso troposférico das estações SPAR e PPTE. No software GIPSY apenas a componente úmida é estimada, enquanto a componente hidrostática permanece constante.

Figura 03 - Série temporal do atraso troposférico para as estações PPTE e SPAR.

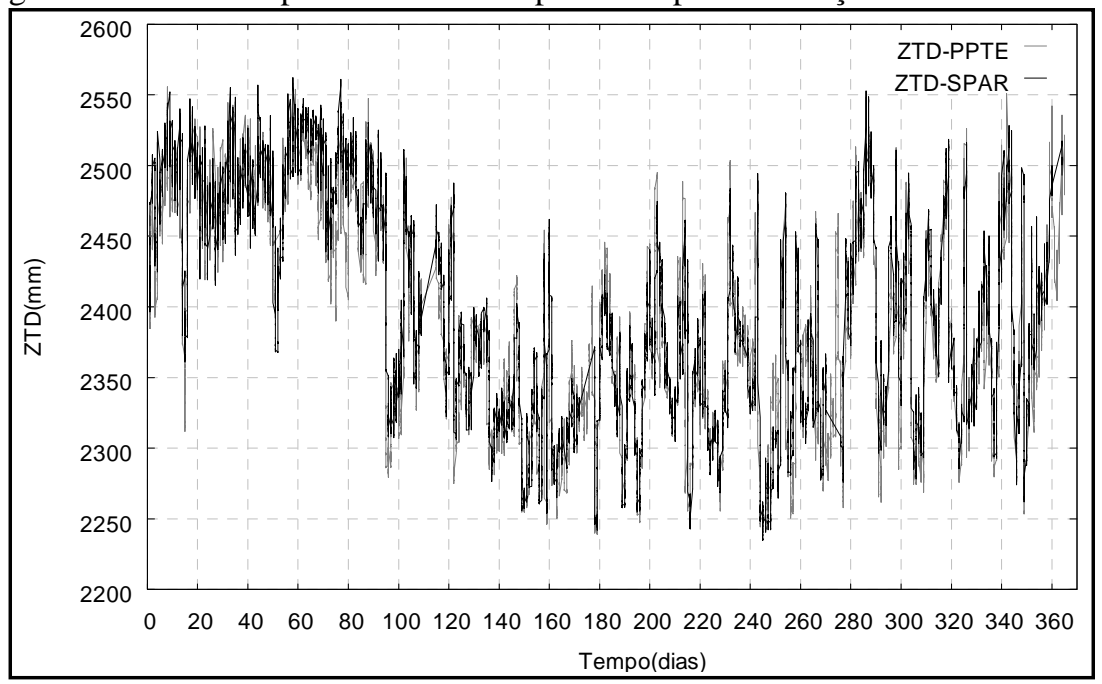

Bol. Ciênc. Geod., sec. Artigos, Curitiba, v. 20, nº 1, p. 39-53, jan-mar, 2014. 
As VRSs foram geradas na posição da estação PPTE, dentre as estações da rede a estação SPAR localiza-se mais próxima à posição da estação PPTE, logo foi adotada como estação base ${ }^{1}$ da rede. Com os dados da estação base SPAR foram gerados os dados da VRS. A partir do cálculo do deslocamento geométrico (DG), juntamente com a aplicação da modelagem troposférica e ionosférica, os dados da VRS foram gerados para a posição da estação PPTE Os dados das estações ILHA, SJRP, ROSA, SPAR e OURI foram utilizados para modelagem do atraso ionosférico na região da rede. Em relação a troposfera, neste artigo foi empregado o modelo empírico de Hopfield e o de PNT/INPE (Seção 4).

Com base na Figura 03 os dados amostrais (arquivos RINEX, com 24 horas de observação) selecionados em períodos úmidos foram referentes aos dias do ano 08, $33,45,58,77,105,106,116,117,146,199,200,202,204,222,252,254,258,259$ e 315. Já em períodos secos os dados RINEX foram dos dias 14, 15, 43, 71, 73, 122, 123, 138, 152, 157, 195, 196, 244, 245, 248, 256, 306, 307, 308 e 314. Posteriormente, foi verificada a qualidade da VRS gerada utilizando os métodos de Posicionamento Absoluto, especificamente o método de Posicionamento por Ponto Preciso (PPP).

Para isso, foi utilizado o software CSRS-PPP (Canadian Spatial Reference System) disponibilizado online pelo NRCan (Natural Resources Canada). Na Tabela 1 são mostradas as siglas empregadas para caracterizar os diferentes modos das VRSs.

Tabela 1 - Significado das siglas para os diferentes modos de VRS.

\begin{tabular}{c|c}
\hline Siglas & Modo de Processamento \\
\hline ARQUIVO REAL & Dados reais da estação PPTE \\
\hline HOP+ NIELL & $\begin{array}{c}\text { VRS gerada com o modelo de Hopfield e a função de } \\
\text { mapeamento Niell }\end{array}$ \\
\hline PNT/INPE + NIELL & $\begin{array}{c}\text { VRS gerada com o modelo de PNT/INPE e a função de } \\
\text { mapeamento Niell }\end{array}$ \\
\hline
\end{tabular}

Os dados das VRSs foram gerados na posição da estação PPTE. Deste modo, espera-se que os dados gerados para as VRSs sejam semelhantes aos dados da estação PPTE (arquivo real).

Os resultados são apresentados em termos de EMQ (Erro Médio Quadrático), onde foi comparada a coordenada de referência da estação com a coordenada obtida.

\section{RESULTADOS E ANÁLISES}

Para verificar a qualidade dos dados das VRSs geradas, conforme descrito na seção 6, foi realizado o PPP no modo estático para os dados amostrais representando as quatro estações do ano.

1 “estação base” está relacionada com a estação da rede mais próxima ao usuário.

Bol. Ciênc. Geod., sec. Artigos, Curitiba, v. 20, no 1, p. 39-53, jan-mar, 2014. 


\subsection{Estação Verão}

A Figura 04 apresenta o EMQ da resultante 3D obtido com os dados da estação PPTE e das VRSs geradas.

Figura 04 - EMQ obtido para a resultante 3D com o PPP no modo estático no período de verão.

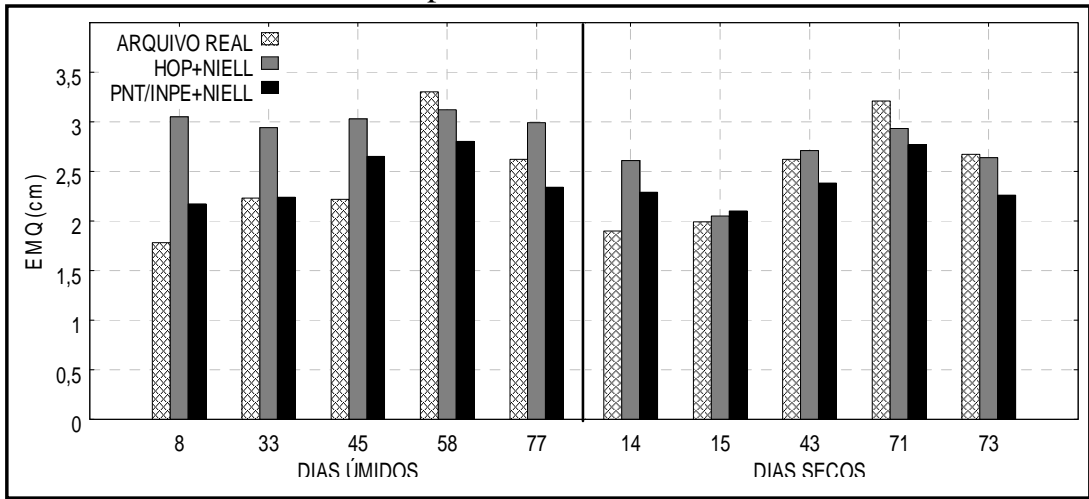

Analisando a Figura 04 é possível observar a melhoria alcançada pela VRS gerada com o modo PNT/INPE+NIELL em comparação com o modo HOP+NIELL para dias úmidos. O EMQ que em média era $3,03 \mathrm{~cm}$ passou para 2,44 $\mathrm{cm}(\mathrm{em}$ média melhoria de 19,5\%) com aplicação de PNT/INPE. Para os dias secos, percebe-se que os melhores resultados também foram obtidos com PNT/INPE+NIELL. O EMQ médio obtido foi de $2,36 \mathrm{~cm}$, o que representa uma melhoria de $8,9 \%$ com uso de PNT/INPE ao invés de Hopfield.

\subsection{Estação Outono}

A Figura 05 apresenta o EMQ médio da resultante 3D para dias úmidos e secos empregando o método de PPP modo estático na estação outono.

Analisando a Figura 05 pode-se notar que os resultados obtidos pelas VRSs são similares aos do arquivo real, exceto para o dia 106. Além disso, para dias úmidos os modelos de Hopfield e PNT/INPE apresentam valores semelhantes. Observou-se que o modelo de Hopfield em média foi apenas $0,1 \mathrm{~cm}$ melhor que o de PNT/INPE. Além disso, pode-se notar que o EMQ médio obtido com o modo PNT/INPE+NIELL foi similar ao arquivo real da estação PPTE. Ainda em relação à Figura 05, para dias secos nota-se que da mesma forma supracitada, a VRS gerada por Hopfield e PNT/INPE apresentaram resultados semelhantes ao arquivo real. Além disso, é possível observar que em dias secos a melhoria alcançada com uso de PNT/INPE+NIELL foi da ordem de 1,6\% em relação a Hopfield. 
Figura 05 - EMQ obtido para a resultante 3D com o PPP no modo estático no período de outono.

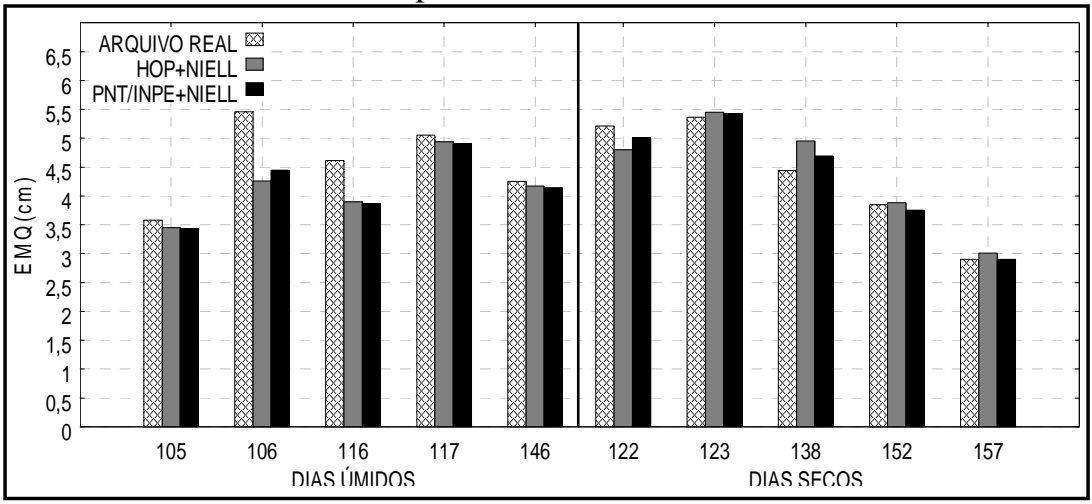

\subsection{Estação Inverno}

A Figura 06 mostra os resultados do EMQ médio para a resultante 3D com os dados da estação PPTE e das VRSs geradas no modo estático para a estação inverno.

Figura 06 - EMQ obtido para a resultante 3D com o PPP no modo estático no período de inverno.

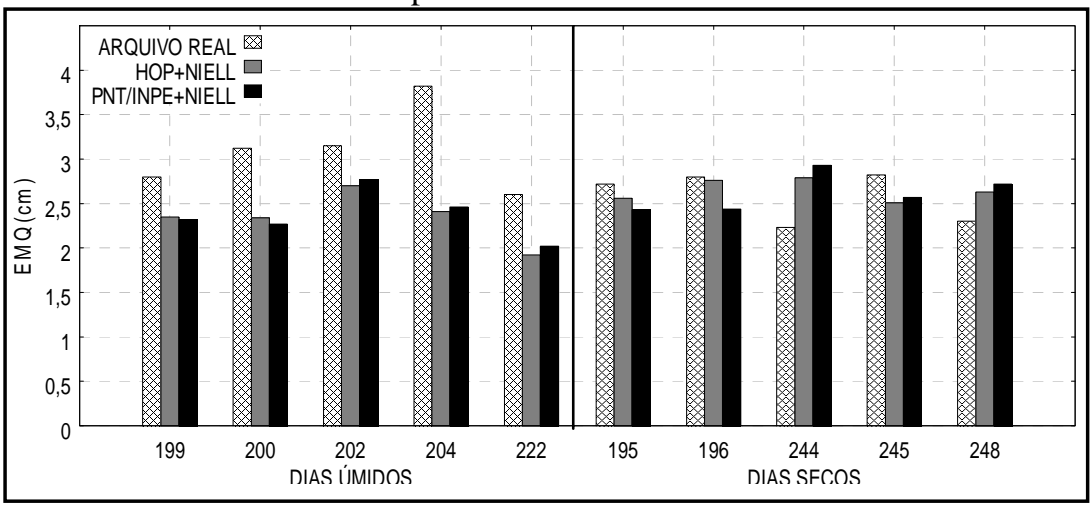

Avaliando a Figura 06 pode-se notar que em dias úmidos o EMQ médio das VRSs geradas nos modos HOP+NIELL e PNT/INPE+NIELL foram similares entre si. No entanto, o modo HOP+NIELL apresentou-se ligeiramente melhor que PNT/INPE. O EMQ médio de 2,37 cm obtido com PNT/INPE passou para 2,34 cm com HOP+NIELL, o que representa uma melhoria de 1,2\% com aplicação de Hopfield. 
Para dias secos verifica-se na Figura 06 que os modos HOP+NIELL e PNT/INPE+NIELL também apresentaram resultados semelhantes. Mas, o modo PNT/INPE+NIELL mostrou desempenho discretamente melhor (EMQ médio de $2,62 \mathrm{~cm}$ ), o que representou uma melhoria de $1,1 \%$ em relação ao modelo de Hopfield. Além do mais, esses resultados foram similares ao obtido pelo arquivo real.

\subsection{Estação Primavera}

A Figura 07 apresenta a comparação entre os valores de EMQ da resultante 3D obtida com o processamento dos dados do arquivo real e das VRSs geradas.

Figura 07 - EMQ obtido para a resultante 3D com o PPP no modo estático no período de primavera.

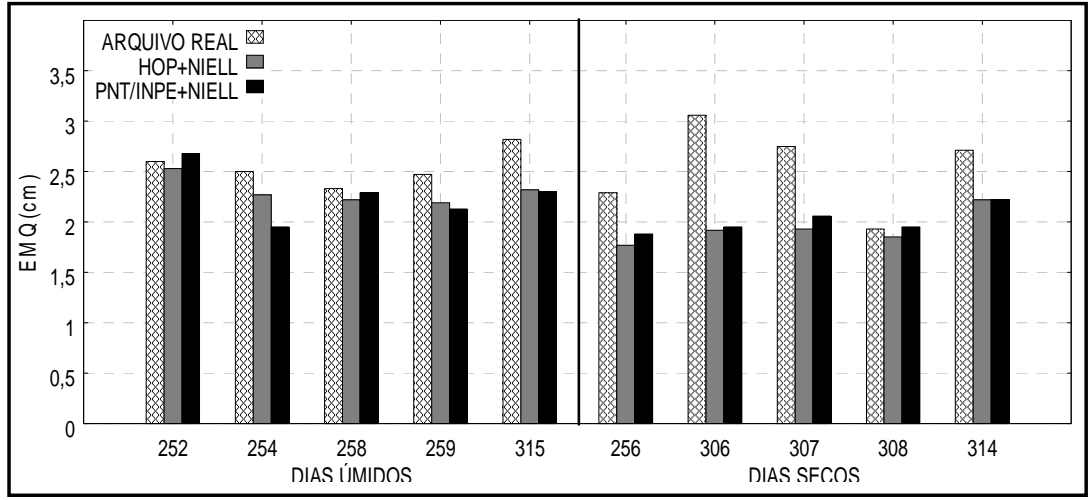

Analisando a Figura 07 percebe-se que em dias úmidos, os modos HOP+NIELL, PNT/INPE+NIELL e o arquivo real são similares. No entanto, com a aplicação do modo PNT/INPE+NIELL o EMQ que em média era $2,31 \mathrm{~cm}$ passou para $2,27 \mathrm{~cm}$. O que representa uma melhoria discreta de $1,7 \%$ com emprego de PNT/INPE+NIELL ao invés do modelo empírico de Hopfield.

Ainda de acordo com os dados da Figura 07, na resultante 3D foi possível notar que os modos HOP+NIELL e PNT/INPE+NIELL são semelhantes para os dias secos. No entanto, o modo HOP+NIELL apresentou melhor desempenho. A melhoria com emprego de Hopfield foi de 3,5\% (em média melhoria de 0,07 cm) com relação ao modelo PNT/INPE.

\subsection{Algumas Considerações}

Nesta seção, o objetivo é comparar os modelos de Hopfield e PNT/INPE na geração de dados da VRS entre as estações do ano. A Figura 08 mostra as discrepâncias encontradas entre os modelos PNT/INPE em relação ao modelo empírico de Hopfield. Nessa figura estão representadas as diferenças dos valores 
médios de EMQ obtidos com Hopfield e PNT. Os valores positivos representam situações onde a PNT obteve um melhor desempenho.

$\mathrm{Na}$ avaliação dos modelos troposféricos em períodos úmidos verifica-se que o modelo de Hopfield foi melhor que o de PNT/INPE em 2 ocasiões das 4 avaliadas no método de PPP. Na estação verão a melhoria alcançada com PNT/INPE foi de $24,2 \%$, e na estação primavera o desempenho de PNT/INPE foi de $1,76 \%$ melhor que Hopfield. Já para as estações outono e inverno, Hopfield apresentou melhor desempenho, as melhorias alcançadas foram de $0,24 \%$ e $1,27 \%$, respectivamente.

Como o modelo de PNT/INPE é baseado em modelagem dinâmica de tempo, conforme descrito na seção 4, e Hopfield um modelo matemático teórico, esperavase que o modelo de PNT/INPE apresentasse melhores resultados que Hopfield em todos os casos, porém isso não aconteceu. Entretanto, as variações encontradas entre os modelos PNT/INPE e Hopfield foram mínimas, melhoria de 0,24\% (aproximadamente $0,01 \mathrm{~cm}$ ) com uso de Hopfield.

Figura 08 - Variações entre o modelo de Hopfield e o modelo de PNT/INPE para dias úmidos e secos.

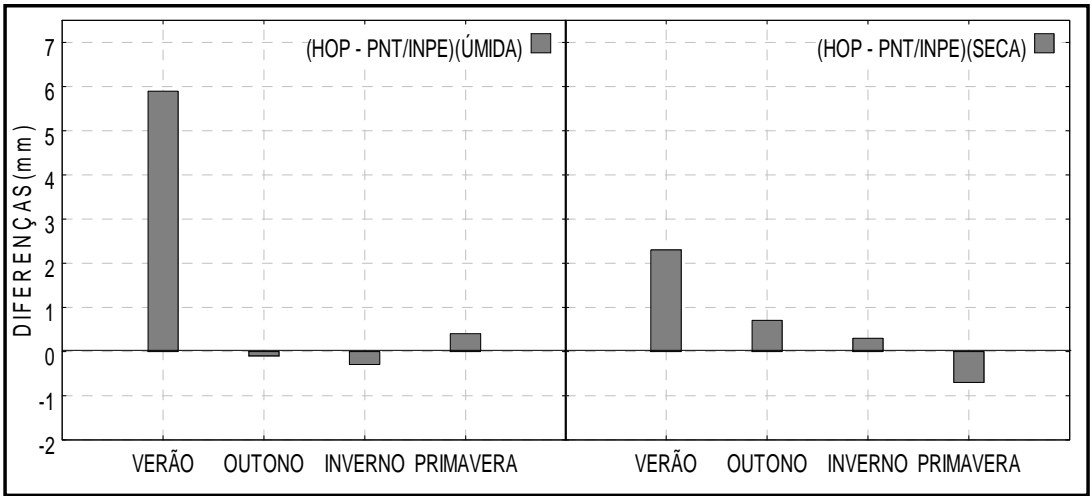

Analisando ainda a Figura 08 é possível observar que em períodos secos o modelo de PNT/INPE foi melhor que o de Hopfield em 3 das 4 ocasiões avaliadas. O modelo de PNT/INPE foi melhor que Hopfield nas estações verão, outono e inverno, sendo que as melhorias encontradas foram de 9,75\%,1,6\% e 1,1\%. Já Hopfield foi melhor na primavera atingindo melhorias de 3,5\%.

\section{CONCLUSÕES}

O objetivo central deste trabalho de analisar a qualidade das VRSs no posicionamento GPS a partir da comparação de diferentes modelos para troposfera foi atingido. Além disso, foi aplicada uma metodologia diferenciada desenvolvida por Alves (2008), que consiste em gerar dados de uma estação de referência virtual sem solucionar o vetor das ambiguidades entre as estações da rede, empregando 
apenas a correção com modelos para atmosfera. A aplicação dessa metodologia pode propiciar resultados com acuracidade na ordem centimétrica para diversas aplicações, como por exemplo, posicionamento em locais com obstáculos naturais (árvores e terrenos montanhosos), navegação terrestre, agricultura de precisão e aplicação em georreferenciamento de imóveis rurais.

Com os testes realizados o modelo de PNT/INPE apresentou resultados satisfatórios, principalmente na estação verão, atingindo melhoria de 19,5\% em relação a Hopfield. Já na estação inverno, o modelo de Hopfield apresentou-se ligeiramente melhor que PNT/INPE. Porém, as diferenças encontradas foram inferiores a $0,03 \mathrm{~cm}$, o que representa $1,27 \%$ de melhoria.

Finalizando, cabe acrescentar que a qualidade da VRS também foi testada com o PPP cinemático e o método de PP (Posicionamento por Ponto). Ademais, os resultados encontrados foram promissores, os EMQs calculados atingiram discrepâncias centimétricas. Uma descrição detalhada sobre os experimentos realizados podem ser encontrados em Oliveira (2013).

\section{AGRADECIMENTOS:}

Este trabalho foi desenvolvido com recursos financeiros da CAPES mediante atribuição da bolsa de mestrado ao primeiro autor. Ademais, os autores agradecem ao CPGCG (Curso de Pós-Graduação em Ciências Geodésicas) e o LGE (Laboratório de Geodésia Espacial) da FCT/UNESP pelo fornecimento dos dados e assistência no desenvolvimento desta pesquisa.

\section{REFERÊNCIAS BIBLIOGRÁFICAS}

AFONSO, A. J.G. Implementação de uma Rede de Estações de Referência GPS para Posicionamento em Tempo Real. Dissertação (Mestrado em Engenharia Geográfica e Geoinformática), Departamento de Matemática, Universidade de Lisboa, Lisboa, 2006.

ALVES, D. B. M. Posicionamento GPS Utilizando o Conceito de Estação Virtual. 2008. 165f. Tese (Doutorado em Ciências Cartográficas) - Universidade Estadual Paulista, Presidente Prudente, SP.

ALVES, D. B. M.; MONICO, J. F. G.; DALBELO, L. F. A. Análise do Modelo Troposférico Empregado na Geração de uma Estação de Referência Virtual Utilizando o Posicionamento por Ponto Preciso. Boletim de Ciências Geodésicas, Curitiba, v. 15, n. 3. p. 373-387, 2009.

ALVES, D. B. M.; MONICO, J. F. G. GPS/VRS Positioning Using Atmospheric Modeling. GPS Solutions, v.15, n. 3, p. 253-261, 2011.

ALVES, P.; AHN, Y.; LACHAPELLE, G. The Effects of Network Geometry on Network RTK Using Simulated GPS Data. In: ION GPS 2003, Oregon Convention Center, Portland. Proceedings..., 2003.

CHEN, X., et al. Trimble RTX, an Innovative New Approach for Network RTK. In: ION GNSS 2011, Portland, Oregon, EUA. Proceedings... 2011. 
DAI, L.; WANG, J.; RIZOS, C.; HAN, S. Predicting Atmospheric Biases for Realtime Ambiguity Resolution in GPS/GLONASS Reference Station Networks. Journal of Geodesy, Berlin v. 76 n¹1/12, p.617-628, 2003.

EULER, H-J.; KEENAN, C. R.; ZEBHAUSER, B. E.; WÜBBENA, G. Study of a Simplified Approach in Utilizing Information from Permanent Reference Station Arrays. In: ION GPS 2001, Salt Lake City, UT, Proceedings... 2001.

HOFMANN-WELLENHOF, B.; LICHTENEGGER, H.; WASLE, E. GNSS Global Navigation Satellite Systems, GPS, GLONASS, Galileo and more. Spring-Verlage Wien, 2008. 501p.

KRUEGER, C. P. Investigações sobre Aplicações de Alta Precisão do GPS no Âmbito Marinho. Tese (Doutorado em Ciências Geodésicas), Curso de PósGraduação em Ciências Geodésicas, UFPR, Curitiba, 1996.

LACHAPELLE, G. e ALVES, P. Multiple Reference Station Approach: Overview and Current Research. Journal of Global Positioning System, v.1, n.2, p.133136, 2002.

LANDAU, H.; VOLLATH, U.; CHEN, X. Virtual Reference Station Systems. Journal of Global Positioning System, v.1, n.2, p.137-143, 2002.

LEANDRO, R., et al. RTX Positioning: The Next Generation of cm-accurate Realtime GNSS Positioning. In: ION GNSS 2011, Portland, Oregon, EUA. Proceedings... 2011.

LEICK, A. GPS Satellite Surveying. New Jersey: John Wiley \& Sons, 2004.

MONICO, J. F. G. Posicionamento pelo GNSS. Descrição, Fundamentos e Aplicações. São Paulo, 2008. Editora UNESP, $2^{a}$ ed.

OLIVEIRA, A. F. Análise Comparativa de Diferentes Modelos Troposféricos para RTK em Rede Usando o Conceito de Estação de Referência Virtual. Dissertação (Mestrado em Ciências Geodésicas), Curso de Pós-Graduação em Ciências Geodésicas, UFPR, Curitiba, 2013.

PRADO, A.; KRUEGER, C. P. Análise da Acurácia nos Posicionamentos Diferenciais Aplicando as Técnicas DGPS e RTK. Revista Brasileira de Cartografia. No 55/01, Julho 2003.

RAMOS, A. M. Aplicação, Investigação e Análise da Metodologia de Reduções Batimétricas através do Método GPS Diferencial Preciso. Dissertação (Mestrado em Ciências Geodésicas), Curso de Pós-Graduação em Ciências Geodésicas, UFPR, Curitiba, 2007.

SAPUCCI, L. F. Estimativa do Vapor D'água Atmosférico e a Avaliação da Modelagem do Atraso Zenital Troposférico Utilizando GPS. 2001. 167f. Dissertação (Mestrado em Ciências Cartográficas) - Universidade Estadual Paulista, Presidente Prudente.

SAPUCCI, L. F.; MONICO, J. F. G.; ESPINOZA, E. S.; MACHADO, L. A. T. Predição do Atraso Zenital Troposférico na América do Sul para Posicionamento GNSS em Tempo Real. In: III Colóquio Brasileiro de Ciências Geodésicas, Paraná, Curitiba, 2003. Anais..., 2003. 
SAPUCCI, L. F.; MONICO, J. F. G.; MACHADO, L. A. T.; ROSA, G. P. S. Avaliação das Previsões do Atraso Zenital Troposférico para a América do Sul obtidas Usando Modelo de Previsão Numérica de Tempo com Alta Resolução Espacial. Boletim de Ciências Geodésicas. v.14, n.4, 2008.

SEEBER, G. Satellite Geodesy: Foundations, Methods, and Applications. Berlin, New York: Walter de Gruyter, 2003.

SEJAS, M. I., KRUEGER, C. P., HECK, B., SEITZ, K. Análise da Qualidade de um Posicionamento Empregando Estações de Referência Virtuais In: Anais do III Colóquio Brasileiro de Ciências Geodésicas - Novos Desenvolvimentos em Ciências Geodésicas, Curitiba, Paraná. Anais..., 2003.

SOARES, W. A. Investigação de uma Modelagem Matemática como Alternativa para Aumento da Área de Cobertura de Estações de Referência DGPS. Tese (Doutorado em Ciências Geodésicas), Curso de Pós-Graduação em Ciências Geodésicas, UFPR, Curitiba, 2005.

SPILKER Jr., J. J. Tropospheric Effects on GPS. In: PARKINSON, B. W.; SPILKER Jr., J. J. Global Positioning System: Theory and Applications. Cambridge: American Institute of Aeronautics and Astronautics, 1996. v.1, p.517-546.

VOLLATH, U., DEKING, A., LANDAU, H. Long-Range RTK Positioning Using Virtual Reference Stations. In: ION GPS 2000, Salt Lake City, Utah. Proceedings... 2000.

ZHANG, K.; ROBERTS C. Network-Based Real-Time Kinematic Positioning System: Current Development in Australia. In: Geoinformatics and Surveying Conference, 2003. The Institute of Surveyor, Malasia. Proceedings..., 2003.

(Recebido em agosto de 2013. Aceito em setembro de 2013). 